\title{
Joaquim Barradas de Carvalho
}

\section{CARLOS GULHERME MOTA}

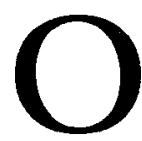

historiador Joaquim Manoel Godinho Braga Barradas de Carvalho (1920-1980) talvez tenha sido o professor estrangeiro que mais deixou marcas de sua passagem por esta cidade. Barradas amava São Paulo.

Foi um intelectual que nos ensinou a pesquisa à lupa, o rigor da escrita, os clássicos. Foi no Brasil, em compensaçáo, que se revelou excelente professor: antes, jamais lecionara. Por seu intermédio, conhecemos, enquanto História viva, as idéias de Jaime Cortesão, de Magalhães Godinho, de Antonio Sérgio, de tantos outros geniais escritores e pensadores portugueses. E entramos em contato com a crítica - gentil e informada - aos estudos de Ameal e de outros menos apreciáveis, que faziam parte de nosso ingênuo currículo universitário.

Espírito anti-acadêmico, anti-ortodoxo, filho de família tradicional alentejana, descendente do Conde das Galvêas e de Camóes, Barradas soube cultivar como ninguém a crítica, temperada sempre pela amizade e empenhada cordialidade, que estendia até mesmo a eventuais oponenetes políticos. Só uma coisa o aborrecia efetivamente: o reacionarismo de alguns de seus compatriotas, cujo comportamento retrógrado empurrou Portugal para o atraso e a melancolia. Daí ter encontrado na vida agitada de São Paulo um clima intelectual e político em que pôde desenvolver suas potencialidades. Tornou-se um paulistano da melhor qualidade: pensava mesmo que se um dia se articulasse um Bloco LusoAfro-Brasileiro, a capital deveria ser Sáo Paulo... Após a Revoluçáo dos Cravos, o Jornal do Brasil dedicou dois ou três éditoriais à utopia barradeana.

Barradas nasceu no dia 13 de junho de $1920 \mathrm{em}$ Arroios, no Alentejo, cujo céu, como diz a canção, não tem sombras (exceto as que vêm do céu). Sua cor morena náo deixava dúvidas quanto ao sangue árabe que lhe corria nas veias. Era o filho mais velho de Manuel Teles Barradas de Carvalho e de Lubélia Godinho Braga Barradas de Carvalho. Nessa família aristocrática, filho de um pai também escritor (autor de Terracampa) e monarquista ilustrado, criou-se uma das personalidades portuguesas mais generosas, abertas, simples e firmes do século XX. 
Joaquim formou-se em História e Filosofia em 1946 pela Faculdade de Letras da Universidade de Lisboa, já revelando a vocaçáo para o campo no qual desenvolveria seus trabalhos: a História das Idéias e, mais precisamente, a História das Mentalidades - que era então uma disciplina menor da História, pouco cultivada e desimportante (segundo parecia). Seu primeiro trabalho foi uma dissertação para aquela Faculdade: Idéias Politicas e Sociais de Alexandre Herculano (1949), no mesmo ano em que veio à estampa outro grande trabalho de outro notável português de sua geração, Antonio José Saraiva, sobre o mesmo Herculano.

Seus estudos e pesquisas prosseguem depois em Paris, onde se doutorou em Estudos Ibéricos pela Faculdade de Letras e Ciências Humanas da Universidade de Paris, Sorbonne, em 1961. Tema de sua tese: Esmeraldo de Situ Orbis, de Duarte Pacheco Pereira. Nesse período, convive intensamente com a escola historiográfica dos Annales, o principal grupo de historiadores europeus capitaneados por Lucien Febvre, Marc Bloch (morto na guerra pelos nazistas) e por Fernand Braudel, sucessor de Febvre e Bloch. Braudel dedicou a Barradas grande estima e a Portugal grande atenção por causa de Magalhães Godinho, Frédéric Mauro e Barradas. Joaquim Barradas foi um discípulo de Braudel (e de Febvre, fundador da História das Mentalidades na França, em memória de quem dedicou seu último livro) e soube combinar o que de melhor havia naquela escola de pensamento com o que de melhor se fazia em termos de pensamento marxista. Excelente mistura, que bateu em cheio na Universidade de Sáo Paulo nos meados dos anos 60, quando intelectuais como Florestan Fernandes, Antonio Cândido, Fernando Henrique Cardoso, Otávio Ianni e inúmeros mais - não nos esqueçamos de Sergio Buarque, Caio Prado Júnior, Cruz Costa e Fernando de Azevedo, da geraçáo antecedente - marcavam o horizonte intelectual e político, desenhando um outro Brasil.

Joaquim sempre foi um militante do Partido Comunista português, porém, extremamente aberto a outras frentes de pensamento progressista. Preocupava-se, como Marx e Braudel, com os quadros mentais que são prisóes de longa duraf̧ão histórica: era o caso de Portugal e o caso do salazarismo que sempre combateu e que o expulsou de sua terra. Mas em Paris soube compor sua vida e honrar seu país e sua cultura. Depois de Paris, o Brasil, onde já estivera - em Salvador - no final nos anos 50 , em um dos famosos congressos do mundo luso-brasileiro, e deixara boa lembrança pessoal e intelectual. No começo dos anos 60 , envolveuse num ataque ao quartel de Beja, o que o obrigou a deixar definitivamente sua pátria (com a cobertura e o apoio de seus pais, vale dizer). 
É na condiçăo de exilado, com passaporte francês e membro da Escola de Altos Estudos, que a Universidade de São Paulo o recebe em 1964, para grande entusiasmo de seus estudantes, fatigados com uma visão tristonha e rançosa da História Ibérica: um rançoso editorial anticomunista no Estadicio, redigido por Santana Mota, o aguardava em seu primeiro dia paulistano. Reunimo-nos indignados - Vitor Ramos, Miguel Urbano Rodrigues, Novais e eu -, na Tudor House, para apoiar os recém-chegados Barradas, Margarida e seus filhos, até porque o jornal tinha a tradição de ajudar exilados portugueses: seus donos, mais Paulo Duarte (amigo de Barradas), tinham se exilado em Portugal durante o Estado Novo brasileiro... Entre nós ficaria ele até 1970, marcando nesses seis anos tantos alunos, colegas e amigos. $O$ golpe de Estado nos irmanava: Portugal e Brasil fechavam-se nas malhas do autoritaris-

Barradas de Carvalho

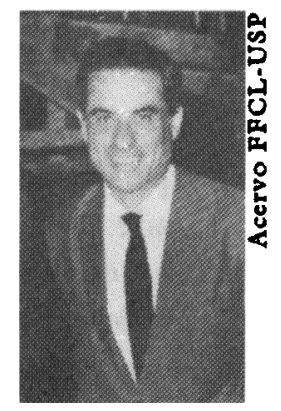

mo, embalados pela doce ilusão do luso-tropicalismo gilbertiano. Do lado de lá do Atlântico, chegavam sons de crítica e de uma série de ensaios que desvendavam os equívocos do oportunismo elitista de certos estudiosos do mundo luso-afro-brasileiro: eram Mario de Andrade ( $\mathrm{Bu}$ anga Fele), Luandino Vieira, Amilcar Cabral e muitos outros.

Após formar uma série de estudantes, dialogar com seus pares Buarque, Cruz Costa, Caio Prado, seus grandes amigos Celso Cunha e Eurípedes Simóes de Paula, Eduardo Portela, Florestan Fernandes, e com os mais novos, como o historiador Fernando Novais, um amigo profundo, Iglésias, Paulo Resende, Bóris Fausto e eu próprio, mais os entáo alunos Jobson Arruda, Arnaldo Contier, Raquel Glezer, Ana Maria Camargo e tantos outros, com seus amigos brasileiros de exílio, como o deputado cassado Fernando Perrone, ou o socib́logo heterodoxo Maurício Tragtemberg, os filósofos Bento Prado e Gianotti, os sociólogos Ianni e Fernando Henrique - e depois de ensinar em todo o lugar por que passava que nossa cultura tinha um recado importante a dar ao mundo, Barradas retorna a Paris. Mas, além de suas pesquisas sobre o 
pensamento português do Renascimento, sobre o século XIX de Herculano ou o século XX de todos nós, Barradas nos informava e era informado sobre uma infinidade de autores: Labrousse, Mandrou, Teyssier, Soboul, Vovelle, Althusser, seu mestre Godinho, seu grande amigo Joel Serrão (que por seu intermédio também se tornaria nosso grande amigo, de Novais sobretudo). Nosso mundo se empobrecera com o golpe de Estado de 1964. Mas como toda História tem sua compensação, Barradas desembarcara no Brasil para iluminar as noites tristonhas do Butantã, e conosco subiu às barricadas da rua Maria Antônia em 1968. Por vezes, como uma espécie de irmão mais velho, alertando contra os excessos, um certo esquerdismo ingênuo que assolava o mundo. Foi com justiça que, em 1983, anos após seu desaparecimento, a Faculdade de Filosofia deu seu nome a uma das salas de aula no campus da Cidade Universitária e, em 1993, a Academia Lusíada consagrou-lhe uma Cadeira. Com Barradas ficava definitivamente plantada uma nova linhagem de História das Mentalidades na bistoriografia brasileira.

Aqui ensinara ele as vantagens da Escola de Paris, mas temperadas pelas preocupaçóes intelectuais de um luso-brasileiro de olho na contemporaneidade. Foi um anfitrião inexcedível, um portugués ao alcance de todos (como costumava dizer), generoso, interessante e interessado: falava horas sobre Braudel, sobre o 5 de outubro, sobre o salazarismo, sobre outros portugueses ilustres no exílio, sobre o jornal Portugal Democrático que aqui era produzido (no qual colaborávamos todos e no qual encontrávamos a verdadeira crônica das maravilhas da presença portuguesa nas colônias). Em tempos difíceis lá e cá, sua casa no Butantã, junto à Cidade Universitária, era um refúgio de inteligência e boa acolhida portuguesa. Uma luz nas trevas. A cultura portuguesa que circulava por sua casa - intelectuais, artistas, professores - não era sombria tampouco, a começar pelo saudoso Vitor Ramos, ex-professor Titular de Literatura Francesa da USP, também exilado. Os exilados em Sáo Paulo constituíam punhado de gente do mais alto nível humano e intelectual, que contrastava com o Portugal oficial e soturno dos jornais nacionais. Aos poucos, íamos conhecendo intelectuais e professores que por aqui passavam (Joel Serrão, Oscar Lopes, Urbano Tavares e muitíssimos outros que se sentavam à bem-posta mesa de sua mulher - Margarida -, também historiadora). Uma casa portuguesa democrática. Juntos, nela recebemos tantos outros amigos, como Frédéric Mauro, os saudosos doyen jacobin Jacques Godechot e o montagnard Alberto Soboul, historiadores notáveis e depois amigos queridos. Era a nossa Repuiblica do Butantã.

Barradas de Carvalho retornou a Paris em 1970, apresentando à Escola de Altos Estudos da Universidade de Paris o ensaio La traduction 
espagnole du Situ Orbis, de Pomponius Mela par Maitre Jean Faras et les notes marginales de Duarte Pacheco Pereira. Em 1975, recebeu a mention très honorable e les félicitations du jury com sua tese de Estado, a mais importante da carreira universitária, recebida com grande impacto, dada sua erudição e importância. Seu título (um dos mais longos da bibliografia mundial...): A la recherche de la spécificité de la Renaissance portugaise - $L$ 'Esmeraldo de Situ Orbis, de Duarte Pacheco Pereira, et la literature portugaise de voyage à $l$ 'époque des grandes découpertes. Contribution à l'étude des origines de la pensée moderne. Foi muito bem recebida por uma comissão de alto nível, presidida pelo historiador Pierre Chaunu que aliás, fez o emocionado e agudo prefácio, com Fernand Braudel Chaunu registra no prefácio da publicação dessa obra jamais ter ocorrido, em sua longa experiência com teses, uma sessão tão emocionante no tradicional Anfiteatro Liard, na Praça da Sorbonne. Sua ediçáo, em dois volumes, pelo escritório de Paris da Fundaçăo Calouste Gulbenkian, foi providenciada pelos vigilantes historiadores, escritores e amigos Joel Serrão e José Blanco.

Barradas produziu mais de $\mathbf{1 0 0}$ artigos, estudos e ensaios, que publicou nas melhores revistas, como Les Annales, Bulletin d 'Etudes Portugaises, Carapelle, Repista de Historia de São Paulo (aqui deixou também muitos trabalhos em colaboraçáo com seus alunos, hoje professores ocupando postos importantes na rede universitária brasileira). Alguns de seus estudos são clássicos, como o relativo à introduçáo dos algarismos arábicos na contabilidade portuguesa, ou sobre a noçáo de experiência no vocabulário português do Renascentismo, ou ainda, sobre a passagem da História-crônica à História-ciência. Mais acessíveis nas livrarias são Portugal e as Origens do Pensamento Moderno (Livros Horizonte, com esclarecedor prefácio de Joel Serrão) e O Obscurantismo Salazarista (Argumentos/Seara Nova). A Revista História \& Crítica (n. 9, junho/julho 1982) dedicou-lhe um número especial, com depoimentos de Luís Albuquerque, Armando Castro, Arnaldo A. Pereira e Luís R. Guerreiro, além de mesa-redonda sobre a obra de Joaquim. Também o professor Victor Gonçalves dedicou-lhe artigo na revista CLIO, do Centro de História da Universidade de Lisboa (no v. II, 1980).

Voltou duas vezes ao Brasil nos anos $70 \mathrm{e}$ em 1979 ensaiamos a organização de um Congresso Luso-Afro-Brasileiro, com a participaçáo de Vitorino Magalhães Godinho, tenente-coronel Melo Antunes, Joel Serrão, Augusto de Bragança, Guilherme Lustosa da Cunha (ex-estudante brasileiro de Barradas, trabalhando para a ONU), Mario de Andrade. Tal empreitada deu certo pela metade, pois num congresso da combativa Sociedade Brasileira para o Progresso da Ciência (Fortaleza, 1979), aqui tivemos Aquino de Bragança, Michel Debrun, Eduardo de 
Oliveira, Fernando Mourão, Severo Gomes e eu discutindo, em perspectivas variadas, os desafios de nossa História comum. Os outros náo puderam vir, pois ensaiavam-se golpes em seus países. Mas por trás de tudo estava o Joaquim...

Seu retorno a Portugal deu-se, em definitivo, após a Revolufắo dos Crapos de 25 de abril de 1974. Náo creio que tenha tido o reconhecimento merecido pela Revoluçáo. Em certa medida, foi o caso também de Joel Serrão, companheiro de geração, um grande intelectual e combatente das horas difíceis, espírito aberto, organizador do grande Dicionário de Historia de Portugal, do qual Barradas participou em diversos verbetes. Só tardiamente foram eles lembrados para postos de relevo e, no caso de Barradas, o governo socialista só postumamente reconheceu seu real valor.

Mas já era tarde. Joaquim falecera em Lisboa a 18 de junho de 1980 , aos 60 anos. Morreu como professor extraordinário, não tendo chegado ao posto mais alto da carreira universitária. Para muitos de nós, brasileiros, ele foi realmente extraordinário, o último romântico português, que procurou um espaço no planeta para sua pátria e para uma utópica comunidade luso-afro-brasileira. Um lugar democrático e moderno, avançado, criativo e fraterno. Os embates entre socialistas e comunistas, mais a escalada do neoliberalismo farsesco modelo comunidade europtia esvaziaram o lugar que Barradas de Carvalho julgava que nossos povos deveriam ocupar na História. E que ele deveria, dizemos nós, ter ocupado na vida pública de seu (nosso país). Como disse o deputado comunista e historiador Victor de Sá na homenagem da Assembléia da República ao historiador falecido, em junho de 1980, Barradas de Carvalho "não investiga os feitos heróicos da força bruta. Sua obra inçidia sobre a capacidade racionalista, crítica e científica do povo português, personificada em alguns heróis, como Duarte Pachedo Pereira - este sim um autêntico herói nacional, autor do também obscuro Esmeraldo de Situ Orbis. Barradas, um homem simples, cientista humilde, foi um grande embaixador da cultura portuguesa junto às intelectualidades francesa e brasileira. Era um homem da congregaçáo dos democratras, dos comunistas e dos socialistas."

O governo português, seu grande amigo de exílio Doutor Mário Soares, e todos nós que tivemos o privilégio de com Barradas aprender alguma coisa, ficamos a lhe dever uma série de iniciativas concretas bolsas para os mais novos, fundaçóes, formação de quadros, publicaçóes sólidas etc. - que aproximem de fato, para além desta hoje intolerável e repetitiva retórica de amizade luso-brasileira de banquetes e de visitas oficiais anódinas e custosas, nossas culturas. Culturas cuja matriz ainda $\epsilon$, apesar de tudo, comum. 
Concluamos com seu mestre francês Fernand Braudel, um dos maiores historiadores deste século, que prefaciou sua grande tese de Estado, cuja publicação infelizmente Barradas năo chegou a ver: "Terei eu razáo de lastimar por Joaquim Barradas de Carvalho, vítima de seu país e de sua época? Um historiador português, para além de tudo, navega na história fantástica de sua pátria e continua, com os gloriosos navegadores, a descobrir o mundo. Mas houve na vida movimentada e por vezes amarga de Joaquim, compensaçóes para o intelectual apaixonado que era. Teria de outro modo sido o historiador magnífico que ele se tornou? Eu digo freqüentemente que náo se compreende Portugal senão no Brasil. Isso é mais verdadeiro ainda, e de longe, para ele do que para mim".

Carlos Guilhore Mot é historiador, professor de História Contemporânea da USP, diretor-fundador do Instituto de Estudos Avançados da USP, criador da Cátedra Jaime Cortesäo no mesmo Instituto e autor de vários livros, entre os quais Atitudes de Inovagáo no Brasil (1789-1801), Nordeste 1817 e Ideologia da Cultura Brasileira. 